\title{
FUZZY NEURAL NETWORK DENGAN NEURON FUZZYKWAN DAN CAI SERTA APLIKASINYA UNTUK EVALUASI KINERJA PERTAHANAN KLUB SEPAK BOLA
}

\author{
Deri Januar dan Mutia Nur Estri \\ Prodi Matematika, Fakultas Sains dan Teknik \\ Universitas Jenderal Soedirman \\ Jl. Dr. Soeparno, Purwokerto, 53122 \\ Email : derijanuarunsoed@gmail.com mutia_ne_yusuf@yahoo.com
}

\begin{abstract}
In this paper, we discuss fuzzy neural network with neuron fuzzy Kwan dan Cai.The algorithm used in this fuzzy neural network is the feed forward algorithm. Futhermore, fuzzy neural network with neuron fuzzy Kwan and Cai can be applied to evaluate a defense performance of football clubs. In this application, we do calculation manually and using a program.
\end{abstract}

Keywords: Fuzzy neural network, neuron fuzzy Kwan dan Cai

ABSTRAK. Pada makalah ini dibahas mengenai fuzzy neural network dengan neuron fuzzy Kwan dan Cai. Algoritma yang digunakan pada fuzzy neural network ini adalah algoritma propagasi maju. Selanjutnya, fuzzy neural network dengan neuron fuzzy Kwan dan Cai diaplikasikan untuk evaluasi kinerja pertahanan klub sepak bola. Pada aplikasi ini, perhitungan dilakukan secara manual maupun menggunakan program.

Kata kunci: Fuzzy neural network, neuron fuzzy Kwan dan Cai

\section{PENDAHULUAN}

Permasalahan yang samar sering menimbulkan kesulitan untuk pengambilan keputusan. Misalnya, di cabang olahraga sepak bola, setiap klub sepak bola menginginkan hasil yang bagus untuk musim yang akan datang. Oleh karena itu, diperlukan evaluasi kinerja klub di musim sebelumnya, seperti evaluasi kinerja pertahanan. Evaluasi ini biasanya hanya dinilai dengan baik, cukup, dan buruk. Padahal, batasan antara kondisi baik, cukup, dan buruk tersebut seringkali samar sehingga perlu adanya solusi untuk mengatasi kesamaran tersebut.

Salah satu solusi untuk mengatasi kesamaran tersebut dapat diperoleh dengan menggunakan soft computing. Soft computing mempunyai empat 
komponen utama pembentuk, yaitu sistem fuzzy, jaringan saraf tiruan, algoritma evolusioner, dan penalaran dengan probabilitas.Terkadang dua atau lebih komponen tersebut digabungkan untuk mendapatkan algoritma yang lebih sempurna (yang biasa disebut sebagai sistem hybrid). Ada beberapa jenis sistem hybrid yang sering dipakai, salah satunya adalah fuzzy neural network (FNN). FNN merupakan model arsitektur jaringan saraf tiruan, namun struktur jaringannya diinterpretasikan dengan sekelompok aturan fuzzy. Aturan fuzzy yang digunakan merupakan operasi-operasi pada logika fuzzy, seperti AND atau $O R$. FNN memiliki elemen pemroses (yang disebut juga neuronfuzzy). Berdasarkan operasi data yang digunakan, neuronfuzzy dibagi menjadi tiga jenis, yaitu neuronfuzzy AND, neuronfuzzy OR, dan neuronfuzzy Kwan dan Cai. Berbeda dengan neuronfuzzy AND dan OR, neuronfuzzy Kwan dan Cai memiliki operasi yang berbeda-beda pada setiap layarnya sehingga neuron fuzzy Kwan dan Cai dapat mengenali pola yang tidak tetap. Oleh karena itu, pada makalah ini akan dibahas tentang FNN dengan neuronfuzzy Kwan dan Cai dan aplikasinya untuk mengevaluasi kinerja pertahanan klub sepak bola.

\section{METODE PENELITIAN}

\subsection{Data}

Data yang digunakan pada makalah ini berupa data sekunder yang diambil dari websiteOfficial Site of Premier League negara Inggris untuk musim 20112012 yang disajikan pada Tabel 1. Pada perhitungan secara manual, data yang digunakan adalah data statistik pertahanan klub LVP. Sementara itu, pada perhitungan menggunakan program, data yang digunakan adalah data seluruh klub pada kompetisi Premier League negara Inggris.

Tabel 1. Data statistik pertahanan klub di kompetisi Premier League negara Inggris untuk musim 2011-2012

\begin{tabular}{|c|l|c|c|c|c|c|c|}
\hline \multirow{2}{*}{ No. } & \multirow{2}{*}{ Klub } & \multicolumn{6}{|c|}{ Kategori pertahanan } \\
\cline { 3 - 8 } & & A & B & C & D & E & F \\
\hline 1 & MNC & 29 & 143 & 2 & 17 & 112 & 222 \\
\hline 2 & MNU & 33 & 189 & 2 & 20 & 130 & 227 \\
\hline 3 & ARS & 49 & 164 & 5 & 13 & 80 & 195 \\
\hline
\end{tabular}




\begin{tabular}{|c|l|c|c|c|c|c|c|}
\hline 4 & TTM & 41 & 168 & 1 & 14 & 115 & 269 \\
\hline 5 & NWC & 51 & 185 & 0 & 15 & 142 & 326 \\
\hline 6 & CLS & 46 & 182 & 1 & 10 & 111 & 242 \\
\hline 7 & EVN & 40 & 157 & 3 & 12 & 119 & 260 \\
\hline 8 & LVP & 40 & 155 & 3 & 12 & 88 & 249 \\
\hline 9 & FLH & 51 & 239 & 1 & 11 & 120 & 285 \\
\hline 10 & WBA & 52 & 203 & 3 & 10 & 168 & 353 \\
\hline 11 & SWC & 51 & 207 & 2 & 14 & 125 & 247 \\
\hline 12 & NWC & 66 & 227 & 1 & 3 & 150 & 422 \\
\hline 13 & SDL & 46 & 187 & 1 & 12 & 158 & 272 \\
\hline 14 & STC & 53 & 198 & 3 & 9 & 128 & 263 \\
\hline 15 & WGA & 62 & 184 & 0 & 8 & 117 & 264 \\
\hline 16 & ASV & 53 & 172 & 2 & 9 & 151 & 372 \\
\hline 17 & QPR & 66 & 176 & 2 & 7 & 134 & 261 \\
\hline 18 & BLT & 77 & 195 & 1 & 3 & 153 & 250 \\
\hline 19 & BLB & 78 & 176 & 3 & 3 & 161 & 457 \\
\hline 20 & WVW & 82 & 244 & 2 & 4 & 133 & 290 \\
\hline Nilai minimum & 29 & 143 & 0 & 3 & 80 & 195 \\
\hline Nilai maksimum & 82 & 244 & 5 & 20 & 168 & 457 \\
\hline
\end{tabular}

\subsection{Prosedur penelitian}

Kajian mengenai FNN dengan neuronfuzzy Kwan dan Cai diambil dari (Kwan dan Cai, 1994). Selanjutnya, FNN dengan neuron fuzzy Kwan dan Cai diaplikasikan pada evaluasi kinerja pertahanan klub sepak bola. Pada aplikasiini, perhitungan dilakukan dengan dua cara, yaitu perhitungan secara manual dan perhitungan menggunakan program. Perhitungan secara manual dilakukan dengan langkah-langkah berikut:

1. Menentukan nilai unit masukan, bobot, dan threshold pada arsitektur jaringan FNN dengan neuron fuzzy Kwan dan Cai.

2. Menentukan operasi-operasi data yang akan digunakan pada proses pembelajaran jaringan FNN dengan neuron fuzzy Kwan dan Cai.

3. Memasukkan nilai unit masukan, bobot, dan threshold yang telah ditentukan ke dalam operasi data untuk dilakukan perhitungan manual.

4. Menganalisis nilai keluaran jaringan FNN dengan neuron fuzzy Kwan dan Cai yang diperoleh dari perhitungan manual. 
Perhitungan menggunakan program dilakukan dengan langkah-langkah berikut:

1. Merancang ekspresi program berdasarkan operasi-operasi data pada FNN dengan neuron fuzzy Kwan dan Cai dengan software Matlab 6.1.

2. Memasukkan nilai tiap unit masukan ke dalam program untuk dilakukan perhitungan program.

3. Menganalisis hasil keluaran jaringan FNN dengan neuron fuzzy Kwan dan Cai yang diperoleh dari perhitungan program.

4. Menganalisis antara hasil keluaran perhitungan manual dan perhitungan program.

\section{HASIL DAN PEMBAHASAN}

\subsection{Fuzzy Neural Network dengan NeuronFuzzy Kwan dan Cai}

FNN merupakan model jaringan yang menggunakan algoritma JST, tetapi arsitekturnya diinterpretasikan dengan konsep-konsep fuzzy. FNN merupakan arsitektur jaringan yang digunakan untuk memproses data-data fuzzy.FNN dengan neuron fuzzy Kwan dan Cai adalah JST yang menggunakan model jaringan layar tunggal. Hal ini berarti, bahwa setiap unit masukan pada jaringan dihubungkan langsung ke unit keluarannya. Operasi data pada arsitektur jaringan FNN dengan neuron fuzzy Kwan dan Cai menggunakan konsep fuzzy.

Arsitektur jaringan FNN dengan neuronfuzzy Kwan dan Cai terdiri dari dua layar, yaitu layar masukan dan layar keluaran, serta empat operasi data propagasi maju (yaitu operasi perkalian, operasi agregasi, operasi aktivasi jaringan, dan operasi fuzzifikasi), seperti disajikan pada Gambar1, yang diambil dari Kusumadewi dan Hartati (2010:155). 


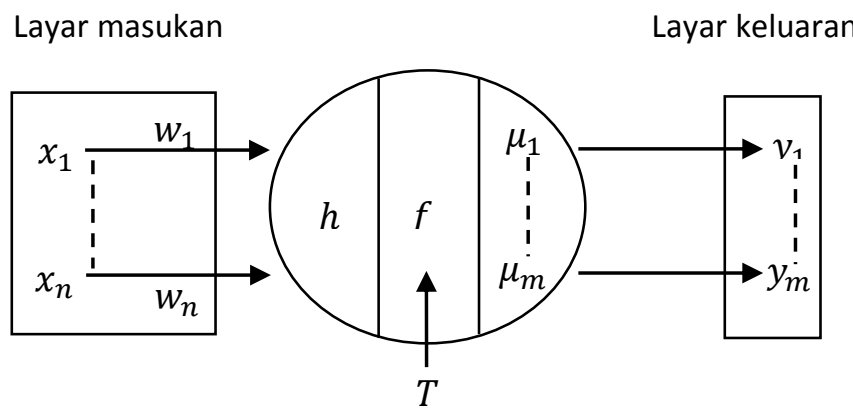

Gambar 1. Arsitektur jaringan FNN dengan neuronfuzzy Kwan dan Cai

Pada Gambar 1, arsitektur jaringan FNN dengan neuronfuzzy Kwan dan Cai terdiri dari $n$ buah unit masukan (yaitu $x_{1}, \cdots, x_{n}$ ), $n$ buah bobot (yaitu $\left.w_{1}, \cdots, w_{n}\right), m$ buah unit keluaran (yaitu $y_{1}, \cdots, y_{m}$ ), dan sebuah nilai ambang batas (threshold) T. Semua nilai pada unit masukan, bobot, dan threshold berupa bilangan riil. Pada unit keluaran, nilai yang dihasilkan berupa bilangan riil yang direpresentasikan dengan derajat keanggotaan yang terletak pada interval $[0,1]$. Selain itu, terdapat sebuah fungsi agregasi yang dilambangkan $h$, sebuah fungsi aktivasi yang dilambangkan $f$, dan $m$ buah fungsi keanggotaan yang dilambangkan $\mu_{j}$, untuk $j=1, \cdots, m$.

Berdasarkan arsitektur jaringan, sistem kerja FNN dengan neuron fuzzy Kwan dan Cai dibagi menjadi tiga langkah.

\section{Langkah pertama}

Menentukan nilai pada unit masukan, bobot, dan threshold. Nilai pada unit masukan, bobot, dan threshold sebaiknya diambil dari interval yang sama. Jika nilai pada tiap unit masukan tidak terletak pada interval yang sama, maka dilakukan transformasi data pada tiap unit masukan.

\section{Langkah kedua}

Menentukan proses pelatihan. Proses pelatihan dilakukan menggunakan algoritma pelatihan dengan propagasi maju. Pada makalah ini, propagasi maju terdiri dari empat tahap operasi data. Keempat tahap operasi data propagasi maju tersebut adalah sebagai berikut:

1. Operasi pertama merupakan operasi perkalian data antara unit masukan $x_{i}$ dan bobot $w_{i}$, untuk $i=1, \cdots, n$. Hasil dari operasi perkalian tersebut berupa 
nilai, yang dilambangkan dengan $p_{i}$. Dengan demikian, operasi perkalian data dapat dirumuskan sebagai

$$
p_{i}=x_{i} w_{i}, \quad i=1, \cdots, n .
$$

2. Operasi kedua merupakan operasi agregasi terhadap nilai $p_{i}$. Hal ini dikarenakan fungsi yang digunakan adalah fungsi agregasi $h\left(p_{l}, \cdots, p_{n}\right)$. Hasil dari operasi agregasi tersebut berupa nilai, yang dilambangkan dengan $z$. Fungsi agregasi $h\left(p_{1}, \cdots, p_{n}\right)$ yang digunakan terdiri dari dua jenis, yaitu maksimum dan minimum. Fungsi agregasi maksimum adalah fungsi yang nilai keluarannya berupa nilai maksimum dari kumpulan nilai $p_{1}, \cdots, p_{n}$. Fungsi agregasi $h\left(p_{1}, \cdots, p_{n}\right)$ maksimum dirumuskan sebagai

$$
z=h\left(p_{1}, \cdots, p_{n}\right)=\max \left(p_{1}, \cdots, p_{n}\right) .
$$

Fungsi agregasi minimum adalah fungsi yang nilai keluarannya berupa nilai minimum dari kumpulan nilai $p_{1}, \cdots, p_{n}$. Fungsi agregasi $\left(p_{1}, \cdots, p_{n}\right)$ minimum dirumuskan sebagai

$$
z=h\left(p_{1}, \cdots, p_{n}\right)=\min \left(p_{1}, \cdots, p_{n}\right) .
$$

3. Operasi ketiga merupakan operasi aktivasi jaringan. Hasil dari operasi aktivasi berupa nilai, yang dilambangkan dengan $s$. Nilai $s$ diperoleh dari hasil fungsi aktivasi terhadap pengurangan antara nilai $z$ dan nilai $T$. Dengan demikian, operasi aktivasi FNN dengan neuron fuzzy Kwan dan Cai dirumuskan sebagai

$$
s=f(z-T) .
$$

4. Operasi keempat merupakan operasi fuzzifikasi terhadap nilai $s$. Hasil dari operasi fuzzifikasi tersebut berupa nilai, yang dilambangkan dengan $y_{j}$, untuk $j=1, \cdots, m$. Nilai $y_{j}$ dirumuskan dengan persamaan

$$
y_{j}=\mu_{j}(s), j=1, \cdots, m \text {. }
$$

$\mu_{j}(s)$ adalah derajat keanggotaan yang ditentukan oleh fungsi keanggotaan.

\section{Langkah ketiga}


Menganalisis nilai pada keluaran jaringan, yaitu $y_{j}$. Langkah ketiga bertujuan untuk menentukan keluaran jaringan yang diinginkan dan memperoleh kesimpulannya.

\subsection{Aplikasi dari FNN dengan Neuron Fuzzy Kwan dan Cai Secara Manual}

Perhitungan secara manual dilakukan dengan langkah-langkah sebagai berikut:

\section{Langkah pertama}

Berdasarkan Tabel 1, diketahui nilai tiap-tiap kategori terletak pada interval yang berbeda-beda. Oleh karena itu, dilakukan transformasi data ke interval yang sama, yaitu $[0,1]$. Selanjutnya, hasil tranformasi ditetapkan sebagai unit masukan yang disajikan pada Tabel 2 .

Tabel 2. Unit masukan jaringan

\begin{tabular}{|c|c|c|c|c|c|c|}
\hline & $x_{1}$ & $x_{2}$ & $x_{3}$ & $x_{4}$ & $x_{5}$ & $x_{6}$ \\
\hline Tim LVP & 0,79 & 0,88 & 0,4 & 0,53 & 0,91 & 0,79 \\
\hline
\end{tabular}

Selanjutnya, nilai pada bobot dan threshold ditentukan berdasarkan tingkat pengaruh tiap kategori, seperti yang disajikan pada Tabel 3.

Tabel 3. Bobot jaringan dan thershold

\begin{tabular}{|c|c|c|c|c|c|c|}
\hline$w_{1}$ & $w_{2}$ & $w_{3}$ & $w_{4}$ & $w_{5}$ & $w_{6}$ & $T$ \\
\hline 0,7 & 0,3 & 0,4 & 0,6 & 0,1 & 0,5 & 0,1 \\
\hline
\end{tabular}

\section{$\underline{\text { Langkah Kedua }}$}

Semua nilai pada unit masukan, bobot, dan threshold diproses ke dalam empat tahap operasi data.

1. Operasi perkalian

$$
\begin{aligned}
p_{1}=x_{1} w_{1} & =(0,79)(0,7)=0,553, \\
p_{2} & =x_{2} w_{2}=(0,88)(0,3)=0,264, \\
p_{3} & =x_{3} w_{3}=(0,4)(0,4)=0,16, \\
p_{4} & =x_{4} w_{4}=(0,53)(0,6)=0,318,
\end{aligned}
$$




$$
\begin{aligned}
p_{5} & =x_{5} w_{5}=(0,91)(0,1)=0,091, \\
p_{6}=x_{6} w_{6} & =(0,79)(0,5)=0,395 .
\end{aligned}
$$

2. Operasi agregasi

$$
Z=\max (0,553 ; 0,264 ; 0,16 ; 0,318 ; 0,091 ; 0,395)=0,553 .
$$

3. Operasi aktivasi jaringan

$$
s=f(0,553-0,1)=f(0,453)=0,453 .
$$

4. Operasi fuzzifikasi

$$
\begin{gathered}
y_{1}=\mu_{\text {Buruk }}(s)=\left\{\begin{array}{lc}
1 ; & (0,35-s) \\
0,25 & s \leq 0,1 \\
0 ; & 0,1<s<0,35
\end{array}\right. \\
y_{2}=\mu_{\text {Cukup }}(s)=\left\{\begin{array}{lc}
0 ; & s \geq 0,35 . \\
\frac{(s-0,1)}{0,25} ; & 0,1<s<0,35 \\
\frac{(0,6-s)}{0,25} ; & 0,35<s<0,6 \\
1 ; \quad & s=0,35 .
\end{array}\right. \\
y_{3}=\mu_{\text {Baik }}(s)=\left\{\begin{array}{lc}
0 ; & s \leq 0,35 \\
\frac{(s-0,35)}{0,25} ; & 0,35<s<0,6 \\
1 ; & s \geq 0,6 .
\end{array}\right. \\
y_{1}=0 ; \quad y_{2}=0,588 ;
\end{gathered}
$$

\section{Langkah Ketiga}

Pada operasi fuzzifikasi, untuk nilai $s=0,453$ diperoleh nilai tiap-tiap unit keluaran, yaitu

$$
y_{1}=0 ; \quad y_{2}=0,588 ; \quad y_{3}=0,412 .
$$

Hal ini berarti bahwa derajat keanggotaan dari $s$ dalam himpunan fuzzy Buruk sebesar 0, derajat keanggotaan dari $s$ dalam himpunan fuzzy Cukup sebesar 0,588, dan derajat keanggotaan dari $s$ dalam himpunan fuzzy Baik sebesar 
0,412 . Dengan kata lain, nilai $y_{2}$ ( yang merupakan derajat keanggotaan dari $s$ dalam himpunan fuzzy "Cukup") adalah nilai keluaran terbesar. Berdasarkan sistem kerja FNN dengan neuron fuzzy Kwan dan Cai, nilai keluaran terbesar yang dipilih menjadi nilai keluaran utama, yaitu nilai $y_{2}$. Dengan demikian, tim LVP dengan nilai $s=0,453$ mempunyai kinerja pertahanan yang cukup untuk musim 2011-2012.

\subsection{Aplikasi dari FNN dengan Neuron Fuzzy Kwan dan Cai Menggunakan Program}

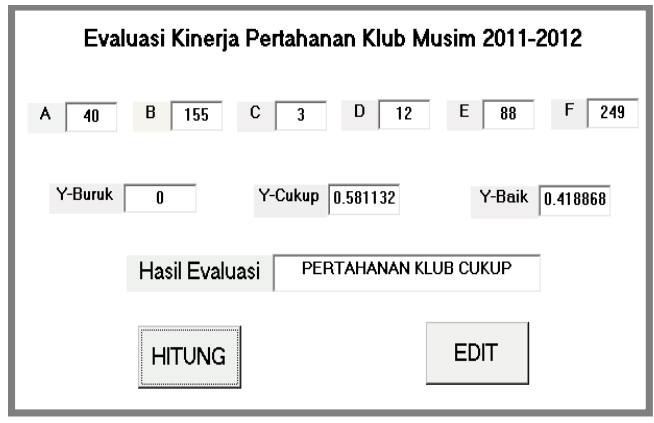

Gambar 2. Tampilan antarmuka hasil perhitungan tim LVP

Pada Gambar 2, untuk tim LVP diperoleh nilai "Y-Buruk" sebesar 0; nilai "Y-Cukup" sebesar 0,581132; dan nilai "Y-Baik" sebesar 0,418868. Pernyataan yang diperoleh pada Gambar 2 untuk "Hasil Evaluasi" menunjukkan bahwa pertahanan klub bernilai cukup. Dengan kata lain, klub LVP mempunyai kinerja pertahanan cukup pada kompetisi Premier League untuk musim 2011-2012.Selanjutnya, perhitungan menggunakan program terhadap evaluasi kinerja pertahanan semua klub dalam kompetisi Premiere League negara Inggris untuk musim 2011-2012 disajikan pada Tabel 4. 
Tabel 4.Hasil perhitungan menggunakan program

\begin{tabular}{|c|c|c|c|c|c|c|c|c|c|c|c|}
\hline \multirow{2}{*}{ No. } & \multirow{2}{*}{ Klub } & \multicolumn{6}{|c|}{ Kategori pertahanan } & \multirow{2}{*}{$\begin{array}{c}\text { Y } \\
\text { Buruk }\end{array}$} & \multirow{2}{*}{$\begin{array}{c}\text { Y } \\
\text { Cukup }\end{array}$} & \multirow{2}{*}{$\begin{array}{c}\mathrm{Y} \\
\text { Baik }\end{array}$} & \multirow{2}{*}{$\begin{array}{c}\text { Hasil } \\
\text { Evaluasi }\end{array}$} \\
\hline & & $A$ & $B$ & $C$ & $D$ & $E$ & $F$ & & & & \\
\hline 1 & MNC & 29 & 143 & 2 & 17 & 112 & 222 & 0 & 0 & 1 & Baik \\
\hline 2 & MNU & 33 & 189 & 2 & 20 & 130 & 227 & 0 & 0,211321 & 0,788679 & Baik \\
\hline 3 & ARS & 49 & 164 & 5 & 13 & 80 & 195 & 0 & 0,8 & 0,2 & Cukup \\
\hline 4 & TTM & 41 & 168 & 1 & 14 & 115 & 269 & 0 & 0,633962 & 0,366038 & Cukup \\
\hline 5 & NWC & 51 & 185 & 0 & 15 & 142 & 326 & 0,105882 & 0,894118 & 0 & Cukup \\
\hline 6 & CLS & 46 & 182 & 1 & 10 & 111 & 242 & 0 & 0,898113 & 0,101887 & Cukup \\
\hline 7 & EVN & 40 & 157 & 3 & 12 & 119 & 260 & 0 & 0,581132 & 0,418868 & Cukup \\
\hline 8 & LVP & 40 & 155 & 3 & 12 & 88 & 249 & 0 & 0,581132 & 0,418868 & Cukup \\
\hline 9 & FLH & 51 & 239 & 1 & 11 & 120 & 285 & 0,162264 & 0,837736 & 0 & Cukup \\
\hline 10 & WBA & 52 & 203 & 3 & 10 & 168 & 353 & 0,215094 & 0,784906 & 0 & Cukup \\
\hline 11 & SWC & 51 & 207 & 2 & 14 & 125 & 247 & 0,162264 & 0,837736 & 0 & Cukup \\
\hline 12 & NRW & 66 & 227 & 1 & 3 & 150 & 422 & 0,52 & 0,48 & 0 & Cukup \\
\hline 13 & SDL & 46 & 187 & 1 & 12 & 158 & 272 & 0 & 0,898113 & 0,101887 & Cukup \\
\hline 14 & STC & 53 & 198 & 3 & 9 & 128 & 263 & 0,267925 & 0,732075 & 0 & Cukup \\
\hline 15 & WGA & 62 & 184 & 0 & 8 & 117 & 264 & 0,2 & 0,8 & 0 & Cukup \\
\hline 16 & ASV & 53 & 172 & 2 & 9 & 151 & 372 & 0,267925 & 0,732075 & 0 & Cukup \\
\hline 17 & QPR & 66 & 176 & 2 & 7 & 134 & 261 & 0,303817 & 0,696183 & 0 & Cukup \\
\hline 18 & BLT & 77 & 195 & 1 & 3 & 153 & 250 & 0,219847 & 0,780153 & 0 & Cukup \\
\hline 19 & BLB & 78 & 176 & 3 & 3 & 161 & 457 & 0,992079 & 0,007920 & 0 & Buruk \\
\hline 20 & WVW & 82 & 244 & 2 & 4 & 133 & 290 & 0,525191 & 0,474809 & 0 & Buruk \\
\hline \multicolumn{2}{|c|}{ Minimum } & 29 & 143 & 0 & 3 & 80 & 195 & & & & \\
\hline \multicolumn{2}{|c|}{ Maksimum } & 82 & 244 & 5 & 20 & 168 & 457 & & & & \\
\hline
\end{tabular}

\section{KESIMPULAN DAN SARAN}

\subsection{Kesimpulan}

FNN dengan neuronfuzzyKwan dan Cai mempunyai arsitektur jaringan yang terdiri dari dua layar, yaitu layar masukan dan layar keluaran. Proses pembelajaran FNN dengan neuronfuzzyKwan dan Cai adalah propagasi maju, yang terdiri dari empat operasi data, yaitu operasi perkalian, operasi agregasi, operasi aktivasi jaringan, dan operasi fuzzifikasi. FNN dengan neuron fuzzy Kwan dan Cai dapat diaplikasikan untuk evaluasi kinerja pertahanan dan hasil aplikasi menunjukkan klub dengan posisi lebih tinggi belum tentu mempunyai kinerja lebih baik dari klub posisi di bawahnya.

\subsection{Saran}

Penelitian lanjut mengenai aplikasi FNN dengan neuronfuzzy dapat dilakukan dengan membandingkanneuron fuzzyKwan dan Cai denganneuronfuzzy OR danneuronfuzzy AND. 


\section{UCAPAN TERIMAKASIH}

Terima kasih penulis sampaikan kepada Dr. Idha Sihwaningrum, M.Sc.St. yang banyak memberikan masukan dan saran pada proses penyusunan makalah ini.

\section{DAFTAR PUSTAKA}

Kwan, H. K. dan Cai, Y., A Fuzzy Neural Network and its Application to Pattern Recognition, IEEE Transaction on Fuzzy Systems 2(3), (2010), 185-192.

Kusumadewi, S. dan Hartati, S., Neuro-Fuzzy, Integrasi Sistem Fuzzy \&Jaringan Syaraf, Yogyakarta, Graha Ilmu,2010. 